\title{
Balanço de compostos nitrogenados e estimativa das exigências de proteína de mantença de bovinos Nelore de três condições sexuais ${ }^{1}$
}

\section{Robson Magno Liberal Véras ${ }^{2}$, Sebastião de Campos Valadares Filho ${ }^{3}$, Rilene Ferreira Diniz Valadares ${ }^{4}$, Luciana Navajas Rennó ${ }^{4}$, Pedro Veiga Rodrigues Paulino ${ }^{3}$, Marjorrie Augusto de Souza ${ }^{5}$}

\author{
1 Parte da tese de Doutorado apresentada à UFV. Projeto financiado pelo CNPq. \\ 2 Universidade Federal Rural da Amazônia - Parauapebas - PA. \\ 3 Departamento de Zootecnia - Universidade Federal de Viçosa. \\ ${ }^{4}$ Departamento de Medicina Veterinária - Universidade Federal de Viçosa. \\ 5 Doutoranda em Zootecnia - UFV.
}

RESUMO - Objetivou-se com este estudo avaliar o efeito de níveis crescentes de PB sobre o balanço de $\mathrm{N}$ e as exigências de proteína metabolizável para mantença em bovinos Nelore. Foram utilizados 12 bovinos Nelore, fistulados no rúmen e no duodeno, de três condições sexuais (quatro fêmeas, quatro machos castrados e quatro machos não-castrados), com idade aproximada de 16 meses e peso corporal médio de 254,8; 285,1 e 265,6 kg, respectivamente. Utilizaram-se três quadrados latinos $4 \times 4$, compostos de quatro animais, quatro níveis de PB (7, 10,13 e 15\%) e quatro períodos. A produção de MS fecal e os fluxos de MS no duodeno foram estimados com a FDA indigestível. A coleta total de urina de

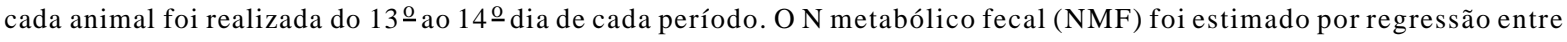
o $\mathrm{N}$ absorvido (Y) e a ingestão de $\mathrm{N}(\mathrm{X})$, expressos em $\mathrm{g} / \mathrm{kg}$ MS. As perdas endógenas urinárias foram estimadas por regressão entre a excreção urinária de $\mathrm{N}(\mathrm{Y})$ e a ingestão de $\mathrm{N}(\mathrm{X})$, expressas $\mathrm{g} / \mathrm{kg}^{0,75}$. As perdas endógenas totais foram estimadas pela regressão entre o balanço de $\mathrm{N}(\mathrm{Y})$ e a ingestão de $\mathrm{N}(\mathrm{X})$, expressas em g/ $\mathrm{kg}^{0,75}$. Houve efeito da condição sexual apenas sobre o $\mathrm{N}$ ingerido, de modo que o consumo foi maior para os machos castrados em relação às fêmeas. A ingestão de compostos nitrogenados, a excreção fecal de $\mathrm{N}$, o $\mathrm{N}$ urinário e o balanço de compostos nitrogenados aumentaram linearmente com os teores dietéticos de PB. Foram registrados valores de 6,69 de N/kgMS ingerida para NMF e de $0,133 \mathrm{gN} / \mathrm{kg}^{0,75}$ para o $\mathrm{N}$ urinário endógeno. A exigência líquida total de proteína foi estimada em $0,431 \mathrm{gN} / \mathrm{kg}^{0,75}$ ou 2,69 g de proteína $/ \mathrm{kg}^{0,75}$. As exigências de proteína metabolizável para mantença, de $4,0 \mathrm{~g} / \mathrm{kg}^{0,75}$, não diferiram entre animais Nelore de diferentes condições sexuais.

Palavras-chave: exigências protéicas, fêmeas, macho castrado, macho não-castrado

\section{Effects of increasing dietary crude protein levels on nitrogen balance and metabolizable protein requirements for maintenance in Nellore cattle}

ABSTRACT- The objective of this trial was to investigate the effects of increasing dietary crude protein levels on $\mathrm{N}$ balance and metabolizable protein requirements for maintenance in Nellore heifers, bulls and steers averaging 16 months of age and body weight of $254.8,285.1$, and $265.6 \mathrm{~kg}$, respectively. Animals were blocked by sexual category (heifers, bulls and steers) and randomly assigned to treatments in three replicated $4 \mathrm{x} 4$ Latin squares. Diets contained the following CP levels: 7, 10, 13, and 15\%. Estimation of fecal DM output and duodenal DM flow was done using the internal marker indigestible ADF. Total collection of urine was conducted from day 13 to day 14 on each period. Metabolic fecal nitrogen, urinary endogenous losses and total endogenous losses were all estimated using a regression approach. No significant effect of sexual category was observed for any of the studied variables, excepting for $\mathrm{N}$ intake that was greater on steers than heifers. $\mathrm{N}$ intake, urinary and fecal $\mathrm{N}$ excretions, and $\mathrm{N}$ balance increased linearly when the dietary $\mathrm{CP}$ level varied from 7 to $15 \%$. Fecal metabolic $\mathrm{N}$ and urinary endogenous $\mathrm{N}$ averaged $6.69 \mathrm{gN} / \mathrm{kg}$ of DMI and $0.133 \mathrm{~g} \mathrm{~N} / \mathrm{kg}^{0.75}$ across diets, respectively. The net protein requirement was estimated as $0.431 \mathrm{gN} / \mathrm{kg}^{0.75}$ or $2.69 \mathrm{~g}$ of protein $/ \mathrm{kg}^{0.75}$. No effect of sexual category on metabolizable protein requirements for maintenance (approximately $4.0 \mathrm{~g} / \mathrm{kg}^{0.75}$ ) was observed in this trial.

Key Words: bull, heifer, protein requirements, steer 


\section{Introdução}

O balanço de N, sob condições controladas, fornece uma estimativa do metabolismo protéico e constitui um método de avaliação dos alimentos e do estado nutricional do animal (Coelho da Silva \& Leão, 1979).

A exigência líquida de nutrientes é representada pelas exigências de mantença e produção, cujas informações adotadas no Brasil referem-se às publicadas pela Academia Nacional de Ciência dos Estados Unidos da América do Norte (NAS), a partir de 1944, denominadas Tabelas de Exigências Nutricionais do NRC (Ezequiel, 1987). A última revisão realizada para bovinos de corte foi descrita pelo NRC (1996).

As pesquisas sobre exigências nutricionais de bovinos em crescimento, no Brasil, iniciaram-se em 1980. Desde então, foram desenvolvidos diversos experimentos para determinar o desempenho, a composição corporal, o ganho de peso e as exigências nutricionais de bovinos em confinamento ou em crescimento/terminação em pastagem (Lana, 2005).

De acordo com Van Soest (1994), a proteína metabolizável (PM) é definida como a quantidade de proteína verdadeira ou de aminoácidos absorvidos no intestino delgadoe, especificamente em ruminantes, é representada pela quantidade de aminoácidos de origem microbiana ou dietética absorvidos no intestino delgado.

Em sistemas de produção de gado de corte, os custos com alimentação animal podem representar 70 a $90 \%$ dos custos operacionais totais dependendo da fase de criação e do nível de produção desejado (Valadares Filho et al., 2005). Portanto, o efeito da nutrição sobre diferentes fatores implica a elaboração de diferentes protocolos para os diversos tipos de manejo, bem como o controle rigoroso dos lotes de manejo e dos grupos contemporâneos (Sainz et al., 2003). Dessa forma, o conhecimento das exigências de proteína para mantença de animais Nelore pode resultar em economia nos custos com formulação de dietas, pela utilização de valores ótimos para as exigências, considerando o elevado custo das fontes protéicas.

No Brasil, foram desenvolvidos poucos trabalhos envolvendo a mensuração das exigências de proteína para mantença. Ezequiel (1987) obteve exigências de proteína metabolizável (PM) para mantença de 1,72 e 4,28 g/kg $\mathrm{PC}^{0,75} /$ dia para novilhos Nelore e Holandês, respectivamente, enquanto Valadares et al. (1997), utilizando a soma das perdas de Nmetabólico fecal e $\mathrm{N}$ urinário endógeno e considerando a eficiência de uso de proteína para mantença igual a 1, obtiveram exigência de proteína metabolizável para mantença de $4,13 \mathrm{~g} / \mathrm{kg} \mathrm{PC}^{0,75} / \mathrm{dia}$ em bovinos anelorados. Ladeira (1998) obteve valor de 1,63 g/kg PC 0,75 / dia em novilhos Nelore.

Nota-se, portanto, que os valores encontrados são bastantes variáveis e diferentes do sugerido pelo NRC (1996), de 3,8 g de PM/ $\mathrm{kg}^{0,75}$, principalmente no caso de animais zebuínos.

Objetivou-se com este trabalho avaliar o balanço de compostos nitrogenados e estimar as exigências de proteína para mantença de bovinos Nelore de diferentes condições sexuais (fêmeas, machos castrados e não-castrados).

\section{Material e Métodos}

O experimento foi conduzido nos Laboratórios de Animais e de Nutrição Animal do Departamento de Zootecnia do Centro de Ciências Agrárias da Universidade Federal de Viçosa, em Viçosa-MG. A fase de campo foi realizada entre maio e outubro de 2004. A cidade de Viçosa está localizada naZona da Mata de Minas Gerais, com 2045'20" de latitude sul, 4552'40" de longitude oeste de Greenwich e altitude de $657 \mathrm{~m}$. A temperatura média, a precipitação pluviométrica e a umidade relativa do ar observadas em 2004 foram de $19,5^{\circ} \mathrm{C}, 1.761 \mathrm{~mm}$ e $82,6 \%$, respectivamente (UFV, 2006).

Foram utilizados 12 animais zebuínos da raça Nelore (quatro de cada condição sexual (fêmeas, machos castrados e machos não-castrados) com peso corporal (PC) médio de 254,8; 285,1; e 265,6 kg, respectivamente. Todos os animais foram fistulados (cânulas de rúmen e tipo T no duodeno) e alojados em baias individuais $\left(9 \mathrm{~m}^{2}\right)$ cobertas, com piso de concreto revestido de borracha, providas de comedouros e de bebedouros individuais.

Os 12 bovinos Nelores foram distribuídos em três quadrados latinos $4 \times 4$, compostos de quatro animais, quatro níveis de $\mathrm{PB}(7,10,13$ e $15 \%)$ e quatro períodos. Os períodos tiveram duração de 15 dias, nove para adaptação às dietas e seis para as coletas. Cada quadrado latino foi constituído por animais de uma condição sexual. As dietas foram compostas de silagem de milho e concentrado nas proporções de 75 e $25 \%$, com base na MS, e balanceadas para conter 7 , 10,13 e $15 \%$ de PB. Os concentrados foram formulados à base de milho, uréia, farelo de algodão ( $38 \%$ de PB) e mistura mineral.

Nas Tabelas 1, 2 e 3 podem ser visualizados a proporção dos ingredientes na mistura dos concentrados, os teores médios de nutrientes dos concentrados e da silagem de milho e a composição química das dietas, respectivamente.

A alimentação foi fornecida duas vezes ao dia, sempre às 8 e 16 h, na forma de mistura completa, à vontade, permitindo-se sobras de, no máximo, 5 a $10 \%$ do fornecido, com água permanentemente à disposição dos animais. A 
quantidade de dieta oferecida foi registrada diariamente e, semanalmente, foram coletadas amostras dos concentrados, por tratamento, da silagem e das sobras, por animal. As amostras semanais foram agrupadas proporcionalmente, em intervalos de seis dias, constituindo-se amostras compostas, as quais foram pré-secas em estufa ventilada a $60^{\circ} \mathrm{C}$ e processadas em moinho com peneira de malha de $1 \mathrm{~mm}$. Todas as amostras foram acondicionadas em sacos plásticos e congeladas para análises posteriores.

As coletas de fezes e digesta de duodeno, aproximadamente $200 \mathrm{~mL}$, obtidas no reto via cânula duodenal, respectivamente, foram feitas uma vez ao dia, simultaneamente, em intervalos de 26 horas, com início às $8 \mathrm{~h}$ do $10^{\mathrm{Q}}$ dia e término às $18 \mathrm{~h}$ do 150 o dia de cada período experimental. As amostras foram armazenadas em sacos plásticos a $-15^{\circ} \mathrm{C}$ e, posteriormente, foram pré-secas em estufa de ventilação forçada a $60^{\circ} \mathrm{C}$, por 72 horas, e processadas em moinho com peneira de malha de $1 \mathrm{~mm}$. Após a pré-secagem das amostras diárias, foi efetuada uma amostra composta com base no peso seco para cada animal em cada período, as quais foram acondicionadas em recipientes plásticos e posteriormente analisadas.

A produção de MS fecal e os fluxos de MS no duodeno foram estimados por meio da FDA indigestível (FDAi), conforme descrito por Berchielli et al. (2005). As amostras de alimentos, sobras, digesta duodenal e fezes foram incubadas no rúmen em sacos de ANKOM (filter bag 57), por 144 horas. Após a incubação ruminal, os sacos foram lavados, fervidos em detergente ácido e secos em estufa com venti-

Tabela 1 - Porcentagem dos ingredientes nos concentrados, em $\%$ da matéria natural

Table 1 - Ingredient composition of the concentrates, as-fed basis (\%)

\begin{tabular}{|c|c|c|c|c|}
\hline \multirow[t]{2}{*}{$\begin{array}{l}\text { Ingrediente } \\
\text { Ingredient }\end{array}$} & \multicolumn{4}{|c|}{$\begin{array}{c}\text { Nível de PB (\%) } \\
\text { CP level (\%) }\end{array}$} \\
\hline & 7 & 10 & 13 & 15 \\
\hline $\begin{array}{l}\text { Fubá de milho } \\
\text { Corn starch }\end{array}$ & 95,2 & 82,3 & 47,2 & 12,0 \\
\hline Farelo de algodão & 0,0 & 10,5 & 45,6 & 80,8 \\
\hline $\begin{array}{l}\text { Cottonseed meal } \\
\text { Uréia } \\
\text { Urea }\end{array}$ & 0,0 & 2,7 & 2,7 & 2,7 \\
\hline Sulfato de amônia & 0,0 & 0,3 & 0,3 & 0,3 \\
\hline $\begin{array}{l}\text { Ammonium sulfate } \\
\text { Mistura mineral }^{1}\end{array}$ & 1,1 & 1,1 & 1,1 & 1,1 \\
\hline $\begin{array}{l}\text { Mineral mix } \\
\mathrm{NaCl} \\
\text { Calcário }\end{array}$ & $\begin{array}{l}1,1 \\
2,0\end{array}$ & $\begin{array}{l}1,1 \\
2,0\end{array}$ & $\begin{array}{l}1,1 \\
2,0\end{array}$ & $\begin{array}{l}1,1 \\
2,0\end{array}$ \\
\hline $\begin{array}{l}\text { Limestone } \\
\text { Total }\end{array}$ & 100 & 100 & 100 & 100 \\
\hline
\end{tabular}

Conteúdo por kg do produto (Content per kg of product): Ca - $240 \mathrm{~g} ; \mathrm{P}-174 \mathrm{~g}$; $\mathrm{Co}-100 \mathrm{mg}$; Cu - $1.250 \mathrm{mg}$; Fe - $1.795 \mathrm{mg}$; F (max.) - $1.740 \mathrm{mg}$; I $90 \mathrm{mg}$; Mn - $2.000 \mathrm{mg} ; \mathrm{Zn}-5.270 \mathrm{mg}$; Se - $15 \mathrm{mg}$ por kilo do produto puro em elementos ativos (per $\mathrm{kg}$ of pure product in active elements).
Tabela 2 - Teores médios de nutrientes dos concentrados e da silagem de milho, expressos na MS

Table 2 - Chemical composition of concentrates and corn silage, DM basis

\begin{tabular}{lccccc}
\hline Item & \multicolumn{3}{c}{$\begin{array}{c}\text { Concentrado } \\
\text { Concentrate }\end{array}$} & $\begin{array}{c}\text { Silagem de milho } \\
\text { Corn silage }\end{array}$ \\
\cline { 2 - 5 } & 7 & 10 & 13 & 15 & \\
\hline MS $(D M)(\%)$ & 88,1 & 88,6 & 89,1 & 89,5 & 23,09 \\
MO $(O M)$ & 93,8 & 93,5 & 92,1 & 90,8 & 92,36 \\
PB $(C P)$ & 7,2 & 18,4 & 28,4 & 38,5 & 6,90 \\
PDR $(R D P)$ & 4,6 & 14,7 & 21,1 & 27,38 & 5,0 \\
PNDR $(R U P)$ & 2,7 & 3,7 & 7,4 & 11,10 & 1,9 \\
EE & 3,7 & 3,3 & 2,5 & 1,6 & 2,28 \\
FDN (NDF) & 10,5 & 13,5 & 24,6 & 35,7 & 52,05 \\
FDA (ADF) & 3,95 & 6,58 & 15,80 & 25,04 & 32,16 \\
FDAi (IADF) & 1,1 & 3,3 & 10,5 & 17,9 & 16,67 \\
CNF (NFC) & 72,4 & 62,35 & 40,65 & 19,05 & 31,13 \\
Lignina (Lignin) & 1,1 & 1,9 & 4,9 & 7,89 & 5,37 \\
\hline
\end{tabular}

Tabela 3 - Composição nutricional das dietas, em \% da MS Table 3 - Chemical composition of the experimental diets, DM basis

\begin{tabular}{|c|c|c|c|c|}
\hline \multirow[t]{2}{*}{ Item } & \multicolumn{4}{|c|}{$\begin{array}{c}\text { Nível de PB (\%) } \\
\text { CP level }\end{array}$} \\
\hline & 7 & 10 & 13 & 15 \\
\hline MS (DM) (\%) & 43,7 & 37,6 & 38,4 & 38,4 \\
\hline $\mathrm{MO}(O M)$ & 92,5 & 91,4 & 92,2 & 93,5 \\
\hline $\mathrm{PB}(C P)$ & 6,7 & 10,0 & 12,9 & 14,2 \\
\hline $\operatorname{PDR}(R D P)$ & 4,9 & 7,4 & 9,0 & 10,6 \\
\hline PNDR (RUP) & 2,1 & 2,3 & 3,3 & 4,2 \\
\hline EE & 2,9 & 2,7 & 2,1 & 2,0 \\
\hline $\operatorname{FDN}(N D F)$ & 37,1 & 43,5 & 46,6 & 50,0 \\
\hline FDA $(A D F)$ & 21,2 & 27,9 & 29,8 & 30,5 \\
\hline $\mathrm{CNF}(N F C)$ & 41,4 & 36,2 & 31,7 & 28,0 \\
\hline $\operatorname{FDAi}(I A D F)$ & 12,4 & 13,9 & 15,6 & 16,3 \\
\hline Lignina (Lignin) & 4,0 & 5,1 & 5,7 & 5,2 \\
\hline $\mathrm{NDT}(T D N)$ & 61,92 & 63,47 & 62,79 & 62,37 \\
\hline
\end{tabular}

lação forçada a $60^{\circ} \mathrm{C}$, por 72 horas, e, depois, em estufa de secagem definitiva, durante meia hora a $105^{\circ} \mathrm{C}$.

A coleta total de urina de cada animal foi realizada do 13 o ao $14^{\circ}$ dia de cada período utilizando-se sondas de Folley no 22 e 26, duas vias, com balão de $30 \mathrm{~mL}$ para novilhas. Na extremidade livre do cateter, foi adaptada mangueira de polietileno, pela qual a urina foi conduzida até um recipiente de plástico com tampa contendo $200 \mathrm{~mL}$ de $\mathrm{H}_{2} \mathrm{SO}_{4}$ a $20 \%$. A urina dos machos foi coletada por intermédio de funis coletores acoplados aos animais, dotados de mangueiras de polietileno que conduziam a urina a um galão plástico com $200 \mathrm{~mL} \mathrm{de}_{2} \mathrm{SO}_{4}$ a $20 \%$. Ao término do período de 24 horas de coleta, a urina foi pesada, homogeneizada, amostrada e armazenada em frascos plásticos a $-15^{\circ} \mathrm{C}$. Para quantificar os compostos nitrogenados na urina, utilizou-se o método semimicro Kjeldahl. 
O N metabólico fecal foi estimado por regressão entre o N absorvido (Y) e a ingestão de N (X), expressos em g/kg MS. As perdas endógenas urinárias foram estimadas por regressão entre a excreção urinária de $\mathrm{N}(\mathrm{Y})$ e a ingestão de $\mathrm{N}(\mathrm{X})$, expressas $\mathrm{g} / \mathrm{kg}^{0,75}$, e as perdas endógenas totais, pela regressão entre o balanço de $\mathrm{N}(\mathrm{Y})$ e a ingestão de $\mathrm{N}$ $(\mathrm{X})$, expressos em $\mathrm{g} / \mathrm{kg}^{0,75}$; todos representados pelo intercepto da equação de regressão (Van Soest, 1994).

As análises de MS, MO, PB, EE, FDN e lignina foram realizadas conforme procedimento descrito por Silva \& Queiroz (2002). As determinações de FDN foram realizadas de acordo com o método descrito por Van Soest \& Robertson (1985), utilizando-se o extrator ANKON200 (Ankom Technology Corp., Fairport, NY, USA). Face à presença de uréia nas dietas, os CNF dos concentrados foram calculados segundo Hall (2000), em que $\% \mathrm{CNF}=100$ $-[(\% \mathrm{~PB}-\% \mathrm{~PB}$ derivada da uréia $+\%$ de uréia $)+\% \mathrm{EE}+$ $\% \mathrm{FDN}+\%$ cinzas].

Os teores NDT foram determinados conforme a equação proposta pelo NRC(2001): $\mathrm{NDT}=\mathrm{PBd}+2,25 \mathrm{EEd}+\mathrm{FDNd}$ $+\mathrm{CNFd}$, em que "d" é o respectivo nutriente digestível.

$\mathrm{O}$ experimento foi analisado segundo delineamento em quadrado latino balanceado para efeitos residuais de tratamento. Os resultados foram avaliados por intermédio do programa SAS (SAS, 1999), adotando-se 0,05 como nível crítico de probabilidade para o erro tipo I. Quando pertinente, as médias foram comparadas pelo teste Tukey.

\section{Resultados e Discussão}

Não houve efeito $(\mathrm{P}>0,05)$ da interação condição sexual $\times$ níveis de proteína sobre o balanço de $\mathrm{N}$ (Tabela 4). A condição sexual influenciou $(\mathrm{P}<0,05)$ apenas a porcentagem de $\mathrm{N}$ ingerido, de modo que o consumo de $\mathrm{N}$ pelos machos castrados foi maior que o das fêmeas. Todavia, não houve diferença no consumo de $\mathrm{N}$ entre machos castrados e nãocastrados $(\mathrm{P}>0,05)$. O maior consumo pelos machos castrados, em relação às fêmeas, pode ser atribuído aos maiores consumos de MS por estes animais.

A ingestão de compostos nitrogenados aumentou linearmente $(\mathrm{P}<0,05)$ com o incremento de $\mathrm{PB}$ nas dietas: no maior nível de PB da dieta (15\%), o consumo médio de $\mathrm{N}$ foi de 134,10 g/dia. Semelhantemente, Rennó (2003) e Cavalcante (2004) verificaram maiores consumos de PB nas dietas com maior concentração protéica.

A excreção fecal de $\mathrm{N}$, assim como o $\mathrm{N}$ urinário e o balanço de compostos nitrogenados, aumentou linearmente com os teores dietéticos de $\mathrm{PB}(\mathrm{P}<0,05)$. No nível de $15 \%$ de PB, foi observada maior excreção de N. O aumento linear de excreção urinária de $\mathrm{N}$ foi de $1,77 \mathrm{~g} /$ dia para cada unidade percentual de aumento de PB na dieta. Valadares et al. (1997) obtiveram excreções médias de $\mathrm{N}$ de 12,27; 18,71;33,88 e 59,92 g/dia para os teores dietéticos de 7; 9,5; 12 e $14,5 \%$ de $P B$, respectivamente, sendo que os dois primeiros não diferiram entre si. Cavalcante (1994), em

Tabela 4 - Médias, equações de regressão (ER) e coeficientes de variação (CV) do balanço de nitrogênio (BN) segundo as condições sexuais e os níveis de PB na dieta

Table 4 - Means, regression equations (ER) and coefficients of variation (CV) of nitrogen balance (NB) according to gender and dietary CP levels

\begin{tabular}{|c|c|c|c|c|c|c|c|c|c|}
\hline \multirow[t]{2}{*}{ Item } & \multicolumn{3}{|c|}{$\begin{array}{c}\text { Condição sexual } \\
\text { Gender }\end{array}$} & \multicolumn{4}{|c|}{$\begin{array}{l}\text { Nível de proteína }(\%) \\
\text { Crude protein level }(\%)\end{array}$} & \multirow[t]{2}{*}{$\begin{array}{l}\mathrm{ER} \\
R E\end{array}$} & \multirow[t]{2}{*}{$\mathrm{CV}(\%)$} \\
\hline & $\mathrm{F}$ & $\mathrm{MC}$ & MNC & 7 & 10 & 13 & 15 & & \\
\hline \multicolumn{10}{|c|}{ Quantidade de N (g/dia) } \\
\hline NI & $85,44 \mathrm{~B}$ & $98,14 \mathrm{~A}$ & $88,7 \mathrm{AB}$ & $51,23 \mathrm{D}$ & $76,82 \mathrm{C}$ & $106,41 \mathrm{~B}$ & $134,10 \mathrm{~A}$ & 1 & 11,2 \\
\hline $\mathrm{NF}$ & $38,10 \mathrm{~A}$ & $41,47 \mathrm{~A}$ & $39,71 \mathrm{~A}$ & $35,97 \mathrm{~B}$ & $38,28 \mathrm{~B}$ & $38,75 \mathrm{~B}$ & $46,99 \mathrm{~A}$ & 2 & 13,3 \\
\hline $\mathrm{NU}$ & 22,67 & 18,83 & 16,16 & $11,54 \mathrm{~B}$ & $13,76 \mathrm{~B}$ & $22,90 \mathrm{AB}$ & $32,28 \mathrm{~A}$ & 3 & 68,1 \\
\hline
\end{tabular}

$\mathrm{g} / \mathrm{kg} \mathrm{MSI}(\mathrm{g} / \mathrm{kg} D M I)$

\begin{tabular}{lllllllll}
$\mathrm{BN}(N B)$ & 5,04 & 6,68 & 6,43 & $0,80 \mathrm{C}$ & $4,75 \mathrm{~B}$ & $8,58 \mathrm{~A}$ & $10,08 \mathrm{~A}$ & 37,7 \\
\hline
\end{tabular}

$\mathrm{F}=$ fêmea $\mathrm{MC}=$ macho castrado; $\mathrm{MNC}=$ macho não-castrado

$\mathrm{NI}=\mathrm{N}$ ingerido; $\mathrm{NF}=\mathrm{N}$ nas fezes; $\mathrm{NU}=\mathrm{N}$ na urina.

$\mathrm{BN}$ em $\mathrm{g} / \mathrm{kg}$ de $\mathrm{MS}$ ingerida $(\mathrm{g} / \mathrm{kg} \mathrm{MSI})$.

Médias, na linha, seguidas de letras diferentes, diferem $(\mathrm{P}<0,05)$ pelo teste Tukey.

Means followed by different letters in the same row differ $(P<0.05)$ by Tukey test.

$F=$ female $; M C=$ bull $; M N C=$ steer

$N I=$ ingested $N ; N F=$ fecal $N ; N U=$ urinary $N$.

$N B$ in $\mathrm{g} / \mathrm{kg}$ of ingested $D M(\mathrm{~g} / \mathrm{kg} D M I)$.

$1 \hat{Y}=-13,32745+9,26219^{*} X\left(r^{2}=0,9828\right)$.

$2 \hat{Y}=25,01233+1,29344^{\star} X\left(r^{2}=0,6522\right)$.

$3 \hat{Y}=-2,84496+1,77124^{*} X\left(r^{2}=0,8431\right)$.

$4 \hat{Y}=-8,18172+1,2783^{*} X\left(r^{2}=0,9816\right)$. 
experimento com dietas contendo 10,$5 ; 12,0 ; 13,5$ e $15 \%$ de $\mathrm{PB}$, não observou diferença na excreção de $\mathrm{N}$ nas fezes e obteve média de 41,77 g/dia.

O balanço de compostos nitrogenados, por sua vez, foi influenciado $(\mathrm{P}<0,05)$ pelos teores de $\mathrm{PB}$ das dietas, observando-se incremento de $1,2783 \mathrm{~g}$ de $\mathrm{N}$ por unidade de acréscimo no teor protéico da dieta, resultado semelhante ao observado por Cavalcante (2004). Valadares et al. (1997) também obtiveram regressão linear entre o balanço de $\mathrm{N}$, expresso em g/dia ou g/kg0,75, e o teor de PB das dietas.

As análises comprovaram alta correlação entre a quantidade de $\mathrm{N}$ absorvido no intestino delgado (Y), em $\mathrm{g} / \mathrm{kg}$ de MS, e o consumo de $\mathrm{N}\left(\mathrm{r}^{2}=0,94\right)$ (Figura 1A). A regressão entre a quantidade de $\mathrm{N}$ absorvido no intestino delgado (Y) e o consumo de $\mathrm{N}(\mathrm{X})$ foi: $\mathrm{Y}=-6,69+0,932(\mathrm{X})$, $\mathrm{P}<0,05$. Com base nesta equação, o intercepto fornece o $\mathrm{N}$ metabólico fecal, que corresponde a 6,69 g de N/kg de MS ingerida, valor superior aos obtidos por Ezequiel (1987),

A

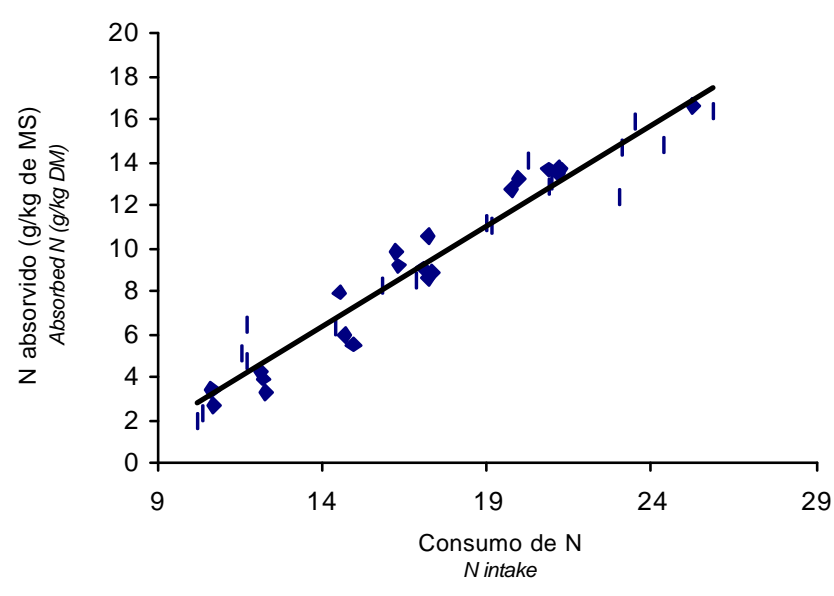

C

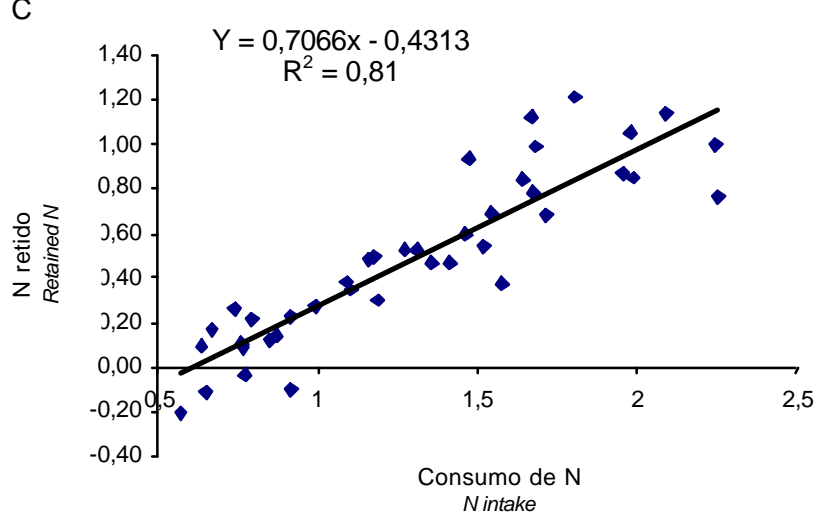

de 4,33 g/kg de MS, em novilhos Nelores; Valadares et al. (1997), de 5,98 g/kg de MS, em novilhos anelorados; e Ladeira et al. (1999) de 5,17 g/kg de MS, em novilhos Nelores não-castrados.

O coeficiente da equação de regressão $(0,932)$ representa a digestibilidade verdadeira da proteína da dieta. Van Soest (1994) encontrou valores de 0,90 a 0,92 para bovinos em revisão sobre diferentes espécies animais. $\mathrm{O}$ NRC (1985) citou, para carneiros e bovinos, absorções verdadeiras de 0,75 e 0,78 , respectivamente, expressas como proporção da quantidade de $\mathrm{N}$ que chegou ao duodeno.

A excreção total urinária $(\mathrm{Y})$ e a ingestão de $\mathrm{N}(\mathrm{X})$, expressas em $\mathrm{g} / \mathrm{kg}^{0,75}$, correlacionaram-se conforme a equação apresentada na Figura $1 \mathrm{~B}(\mathrm{P}<0,05)$. O intercepto corresponde ao NUE, que foi igual a $0,133 \mathrm{gN} / \mathrm{kg}^{0,75}$. Esse valor foi inferior aos observados por Valadares (1997), de $0,22 \mathrm{gN} / \mathrm{kg}^{0,75}$, e Ladeira et al. (1999), de $0,38 \mathrm{gN} / \mathrm{kg}^{0,75}$.

B

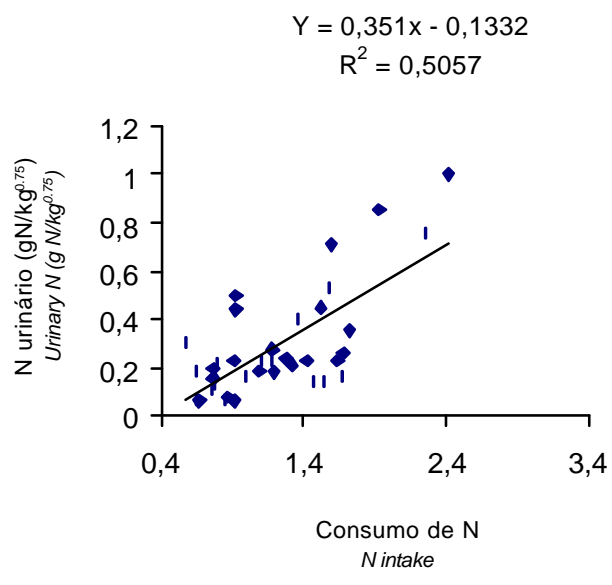

D

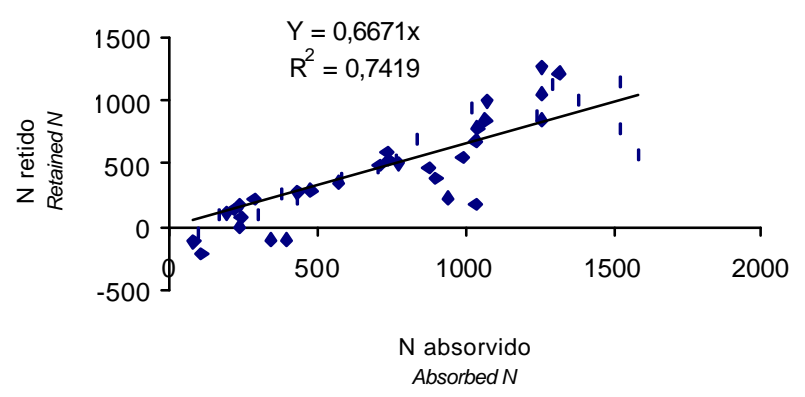

Figura 1 - Relação entre o consumo de N e (A) a quantidade de N absorvido no intestino delgado, em g/kg de MS; (B) a excreção de Nurinário, em g N/kg ${ }^{0,75}$; (C) e $\mathrm{N}$ retido ( $\mathrm{g} / \mathrm{kg}^{0,75}$ ); e entre (D) o $\mathrm{N}$ retido e o $\mathrm{N}$ absorvido.

Figure 1 - Relationship between $N$ intake and $(A)$ amount of $N$ absorbed in the small intestine, expressed as $\mathrm{g} / \mathrm{kg} D M$; (B) urinary $N$ excretion, expressed as $\mathrm{gN} / \mathrm{kg}^{0.75}$; and $(C)$ retained $N\left(\mathrm{~g} / \mathrm{kg}^{0.75}\right)$; and between $(D)$ retained $N$ and absorbed $N$. 
A equação de regressão (Figura 1C) obtida entre o $\mathrm{N}$ retido e o consumo de $\mathrm{N}$, expressos em $\mathrm{gN} / \mathrm{kg}^{0,75}$, resultou em um intercepto de $0,431 \mathrm{gN} / \mathrm{kg}^{0,75}$ ou 2,69 g de proteína/ $\mathrm{kg}^{0,75}$. Esse valor foi maior que o citado pelo AFRC (1993), de 2,3, porém superior ao encontrado por Valadares et al. (1997), de 0,246 gN/kg 0,75 .

A estimativa da eficiência de utilização do $\mathrm{N}$ retido (Figura 1D) em relação ao $\mathrm{N}$ absorvido, de 0,667 , foi muito próxima à recomendada pelo NRC (1985), de 0,67. Utilizando-se esse valor de eficiência e considerando as exigências líquidas de proteína para mantença de $0,431 \mathrm{gN} / \mathrm{kg}^{0,75}$ ou 2,69 g de proteína $/ \mathrm{kg}^{0,75}$, obtém-se exigência de proteína metabolizável de 4,03 g/ $\mathrm{kg}^{0,75}$, próxima ao valor recomendado pelo NRC (1996), de $3,8 \mathrm{~g} / \mathrm{kg}^{0,75}$.

\section{Conclusões}

$\mathrm{O}$ balanço de $\mathrm{N}$ elevou-se linearmente com o aumento dos níveis de PB na dieta. A exigência líquida de proteína para mantença foi estimada em $0,431 \mathrm{gN} / \mathrm{kg}^{0,75}$ ou 2,69 g de proteína $/ \mathrm{kg}^{0,75}$. A exigência de proteína metabolizável para mantença de animais Nelore de diferentes condições sexuais foi de $4,0 \mathrm{~g} / \mathrm{kg}^{0,75}$.

\section{Agradecimento}

À professora Maria Ignês Leão, pela fistulação dos animais.

Aos estagiários Danielle, João Paulo, Mozart, Marcos e Cláudia e à doutoranda Analívia, pelo auxílio na condução do experimento.

\section{Literatura Citada}

AGRICULTURAL AND FOOD RESEARCH COUNCIL - AFRC. Energy and protein requirement of ruminants. Wallingford: CAB International, 1993. 159p.

BERCHIELLI, T.T.; OLIVEIRA, S.G.; CARRILHO, E.N.V.M. et al. Comparação de marcadores para estimativas de produção fecal e de fluxo de digesta em bovinos. Revista Brasileira de Zootecnia, v.34, n.3, p.987-996, 2005.

CAVALCANTE, M.A.B. Níveis de proteína bruta em dietas de bovinos de corte: consumo, digestibilidade, produção microbiana, parâmetros ruminais e desempenho produtivo. Viçosa, MG: Universidade Federal de Viçosa, 2004, 58p. Tese (Doutorado em Zootecnia) - Universidade Federal de Viçosa, 2004.

COELHO DA SILVA, J.F.; LEÃO, M.I. Fundamentos de nutrição dos ruminantes. Piracicaba: Livroceres, 1979. 380p.

EZEQUIEL, J.M.B. Exigências de proteína e minerais de bovídeos: frações endógenas. Viçosa, MG: Universidade Federal de Viçosa, 1987. 131p. Tese (Doutorado em Zootecnia) - Universidade Federal de Viçosa, 1987.
HALL, M.B. Calculation of non-structural carbohydrate content of feeds that contain non-protein nitrogen. Gainesville: University of Florida, 2000. p.A-25 (Bulletin, 339).

LADEIRA, M.M. Consumo, digestibilidades aparentes totais e parciais de dietas contendo diferentes níveis de concentrado, em novilhos Nelore. Viçosa, MG: Universidade Federal de Viçosa, 1998. 69p. Dissertacao (Mestrado em Zootecnia) - Universidade Federal de Viçosa, 1998.

LADEIRA, M.M.; VALADARES FILHO, S.C.; LEÃO, M.I. et al. Consumo e digestibilidades aparentes totais e parciais de dietas contendo diferentes níveis de concentrado, em novilhos Nelore. Revista Brasileira de Zootecnia, v.28, n.2, p.395-403, 1999.

LANA, R.P. Nutrição e alimentação animal (mitos e realidades). 1.ed. Viçosa, MG: Universidade Federal de Viçosa, 2005. 344p.

NATIONAL RESEARCH COUNCIL - NRC. Ruminant nitrogen usage. Washington, D.C.: National Academy of Sciences, 1985. $148 \mathrm{p}$.

NATIONAL RESEARCH COUNCIL - NRC. Nutrient requirements of beef cattle. 7.ed. Washington, D.C.: National Academy Press, 1996. 242p.

NATIONAL RESEARCH COUNCIL - NRC. Nutrient requirements of dairy cattle. 7.ed. Washington, D.C: National Academy Press, 2001. 381p.

RENNÓ, L.N. Consumo, digestibilidade total e parcial, produção microbiana, parâmetros ruminais e excreções de uréia e creatinina em novilhos alimentados com dietas contendo quatro níveis de uréia ou dois níveis de proteína. Viçosa, MG: Universidade Federal de Viçosa, 2003. 252p. Tese (Doutorado em Zootecnia) - Universidade Federal de Viçosa, 2003.

STATISTICAL ANALYSES SYSTEM - SAS. SAS/STAT: user's guide (Release 8.0). Cary: 1999.

UNIVERSIDADE FEDERAL DE VIÇOSA - UFV. Departamento de Engenharia Agrícola. Estação Meteorológica. Viçosa, MG: 2006. n. p.

SAINZ, R.D.; ARAUJO, F.R.C.; MANICARDI, F. et al. Melhoramento genético da carcaça em gado zebuíno. In: SEMINÁRIO NACIONAL DE CRIADORES E PESQUISADORES, 12., 2003, Ribeirão Preto. Anais... Ribeirão Preto: 2003.

SILVA, D.J.; QUEIROZ, A.C. Análises de alimentos: métodos químicos e biológicos. 3 ed. Viçosa, MG: Universidade Federal de Viçosa, 2002. 235p.

VALADARES, R.F.D. Níveis de proteína em dietas de bovinos: consumo, digestibilidade, eficiência microbiana, amônia ruminal, uréia plasmática e excreções de uréia e creatinina. Belo Horizonte: Universidade Federal de Minas Gerais, 1997. 103p. Tese (Doutorado em Ciência Animal) Universidade Federal de Minas Gerais, 1997.

VALADARES, R.F.D.; GONÇALVES, L.C.; SAMPAIO, I.B. et al. Níveis de proteína bruta em dietas de bovinos. 2. Consumo, digestibilidade e balanço de compostos nitrogenados. Revista Brasileira de Zootecnia, v.26, v.6, p.1259-1263, 1997.

VALADARES FILHO, S.C.; PAULINO, P.V.R.; SAINZ, R.D. Desafios metodológicos para determinação das exigências nutricionais de bovinos de corte no Brasil. In: REUNIÃO ANUAL DA SOCIEDADE BRASILEIRA DE ZOOTECNIA, 42 ., 2005, Goiânia. Anais... Goiânia: Sociedade Brasileira de Zootecnia, 2005. p.261-287.

Van SOEST, P.J.; ROBERTSON, J.B. Analysis of forages and fibrous foods. Ithaca: Cornell University, 1985. 202p.

Van SOEST, P.J. Nutritional ecology of the ruminant. 2.ed. London: Comstock Publishing Associates, 1994. 476p.

Recebido: 04/04/06 Aprovado: 26/03/07 